\title{
Effect of statins on breast cancer recurrence and mortality: a review
}

This article was published in the following Dove Press journal:

Breast Cancer - Targets and Therapy

\author{
Renae D Van Wyhe ${ }^{1,2}$ \\ Omar M Rahal' \\ Wendy A Woodward' \\ 'Department of Radiation Oncology, \\ The University of Texas MD Anderson \\ Cancer Center, ${ }^{2}$ Baylor College of \\ Medicine, Houston, TX, USA
}

\begin{abstract}
Statins, or 3-hydroxy-3-methylglutaryl-coenzyme A reductase inhibitors, are medications that have been used for decades to lower cholesterol and to prevent or treat cardiovascular diseases. Since their approval by the US Food and Drug Administration in the 1980s, other potential uses for statins have been speculated on and explored. Basic science and clinical research suggest that statins are also effective in the management of breast cancer. Specifically, in various breast cancer cell lines, statins increase apoptosis and radiosensitivity, inhibit proliferation and invasion, and decrease the metastatic dissemination of tumors. Clinical trials in breast cancer patients support these laboratory findings by demonstrating improved local control and a mortality benefit for statin users. A role for statins in the management of aggressive breast cancers with poor outcomes - namely, inflammatory breast cancer and triple-negative breast cancer - is particularly implicated. However, data exist showing that statins may actually promote invasive breast disease after long-term use and thus should be prescribed cautiously. Furthermore, a general consensus on the type of statin that should be administered, for how long, and when in relation to time of diagnosis is lacking. Given their low toxicity profile, affordability, and ease of use, consideration of statins as a therapy for breast cancer patients is imminent. In this review, we summarize current evidence regarding statins and clinical breast cancer outcomes, as well as discuss potential future studies that could shed light on this increasingly relevant topic. Keywords: statins, HMG-CoA reductase inhibitors, breast cancer, inflammatory breast cancer, triple-negative breast cancer, locoregional recurrence
\end{abstract}

\section{Introduction}

Excluding dermatologic cancers, breast cancer is the most frequently diagnosed cancer among US women. In 2017, invasive breast disease is expected to account for $30 \%$ of all newly diagnosed cancers in women and to cause $16 \%$ of deaths in those affected. ${ }^{1}$ The current treatment regimen for breast cancer is multidisciplinary. Depending on the stage and histology of the cancer, patients may receive a combination or all of the following modalities: surgery, radiotherapy, chemotherapy, hormonal therapy, targeted therapy, and immunotherapy. Although a comprehensive approach is often necessary in order to eradicate disease, breast cancer treatment protocols can sometimes prove too cumbersome, distressing, and even, at times, toxic for the patient to complete successfully. Treatment noncompliance or the premature discontinuation of therapy has been reported to negatively affect outcomes. ${ }^{2-5}$ Given these obstacles, as well as the high mortality rate of aggressive breast cancers, consideration of other effective therapies is thus of paramount importance.
Correspondence: Wendy A Woodward Department of Radiation Oncology, The University of Texas MD Anderson Cancer Center, 1515 Holcombe Boulevard, Unit 1202, Houston, TX 77030, USA

$\mathrm{Tel}+\mathrm{I} 7135632300$

Fax +I 7135636940

Email wwoodward@mdanderson.org 
Statins, also known as 3-hydroxy-3-methylglutaryl-coenzyme A (HMG-CoA) reductase inhibitors, are a class of lipidlowering medications that block the conversion of HMG-CoA to mevalonic acid, which under normal circumstances ultimately yields cholesterol as a part of the mevalonate pathway. Historically, statins have been marketed and prescribed for the primary and secondary prevention of cardiovascular disease, and their current use is widespread. According to a report by the Centers for Disease Control and Prevention in 2014, 23.6 and $38.9 \%$ of women over 45 or 75 years, respectively, were taking statins. ${ }^{6}$ Due to their growing popularity over the past 2 decades, generic statin medications now cost $<\$ 12 /$ month and represent an affordable lipid-lowering agent for individuals at risk of developing heart disease or heart disease-related complications. ${ }^{7}$ Beyond their cardiovascular effects, however, statins have been reported to have possible benefits regarding immunomodulation in autoimmune diseases and organ transplantation, induction of bone marrow stimulation, and inhibition of cancer progression. ${ }^{8-11}$ Their role in breast cancer recurrence and mortality is of particular interest. Preclinical and clinical data exist to support a beneficial role for their use in breast cancer management. However, other studies are less promising and argue against the prescription of statins for purposes not related to cardiovascular disease. Furthermore, results differ depending on the type of statin used, ie, lipophilic (simvastatin, lovastatin, and atorvastatin) vs hydrophilic (pravastatin, rosuvastatin, and fluvastatin). In the following article, we summarize current findings regarding the effect of statins on breast cancer clinical outcomes and provide insight on potential future studies needed for this important topic.

\section{Clinical data regarding the use of statins in breast cancer management}

Several studies suggest a role for statin therapy in breast cancer management; however, the type of statin used, when it is used with respect to time of diagnosis, duration of treatment, follow-up time, and patient cohort characteristics differ significantly in these reports. Thus, it is important to consider all the findings together.

\section{Statins and breast cancer recurrence rates and prognosis}

Clinical data suggest that statins reduce breast cancer recurrence rates when administered postdiagnostically. In one prospective study of 1,945 early-stage breast cancer survivors, initiation of statin use $<3$ years after diagnosis was independently associated with decreased 5 -year breast cancer recurrence rates in a duration-dependent manner. It is important to note that $98 \%$ of the statins prescribed were lipophilic statins, ie, lovastatin (84.4\%), simvastatin (10.9\%), and atorvastatin $(2.5 \%){ }^{12}$ Similarly, in a nationwide, population-based prospective study, Ahern et al found that in women diagnosed with stages I-III breast cancers, patients who took simvastatin in particular after diagnosis experienced 10 fewer breast cancer recurrences per 100 women after 10 years of follow-up. Low outcome frequency precluded the authors from modeling recurrence associations for the exclusive use of the other lipophilic statins. After accounting for potential confounders, hydrophilic statin use was not associated with recurrence outcomes. ${ }^{13}$ Findings from Manthravadi et al's ${ }^{14}$ meta-analysis were in agreement with those from the study by Ahern et al, namely, that a recurrence-free survival benefit was observed for lipophilic statin use only.

Even short-term statin therapy administered after diagnosis may be beneficial. In a retrospective study of 703 stage II/III breast cancer patients, Chae et al found that statin use for as little as 6 months after the initial diagnosis was independently associated with a reduced likelihood of recurrence out to 4.5 years, especially when combined with angiotensinconverting enzyme inhibitors or angiotensin receptor blockers. Interestingly, the majority of patients in this study took atorvastatin $(60.2 \%)$, followed by simvastatin (17.2\%), lovastatin $(10.2 \%)$, and pravastatin $(7.8 \%)$, perhaps suggesting that no one statin is superior regarding breast cancer recurrence outcomes. ${ }^{15}$ This idea is supported by Boudreau et al, who, in a prospective cohort study of 4,216 women diagnosed with stage I/II breast cancer, reported similar adjusted outcomes for a second breast cancer event (SBCE) between lipophilic and hydrophilic statin users. For all statin users, the authors found a nonsignificant reduced risk of an SBCE. ${ }^{16}$ Finally, regarding recurrence, in a retrospective study with the most extensive follow-up, Sakellakis et a ${ }^{17}$ found that statin users had a longer mean relapse-free survival by $\sim 6$ years, and younger statin users ( $<56$ years old) were observed to benefit the most by $\sim 10$ years as compared with other users (refer Table 1 for an overview of the association between statin use and risk of recurrence after multivariate analysis).

The effect of statins on progression-free survival (PFS), overall survival (OS), and disease-specific survival for inflammatory breast cancer (IBC), an especially aggressive subtype, was retrospectively examined. Interestingly, and contrary to most reports for other breast cancers, a longer PFS was independently observed for patients taking 
Table I Overview of the association between statin use and risk of recurrence after multivariate analysis

\begin{tabular}{|c|c|c|c|c|c|c|c|}
\hline Study & Type & $\mathbf{N}$ & Stage & Statins & Recurrence & & \\
\hline \multirow[t]{3}{*}{ Kwan et al ${ }^{12}$} & Prospective & 1,945 & I-IIIA & Lipophilic (97.8\%) & & $\mathrm{RR}$ & $95 \% \mathrm{Cl}$ \\
\hline & & & & Hydrophilic (2.2\%) & $>100$ days & 0.67 & $0.39-1.13$ \\
\hline & & & & & $>2$ years & 0.38 & $0.12-1.19$ \\
\hline \multirow[t]{7}{*}{ Ahern et $\mathrm{al}^{13}$} & Prospective & 18,769 & I-III & Lipophilic (77.6\%), simvastatin (7I.7\%) & & $\mathrm{HR}$ & $95 \% \mathrm{Cl}$ \\
\hline & & & & Hydrophilic (22.3\%) & 5-Year lipophilic & 0.7 & $0.53-0.92$ \\
\hline & & & & & 5-Year simvastatin & 0.62 & $0.46-0.84$ \\
\hline & & & & & 5-Year hydrophilic & I.I & $0.7-1.80$ \\
\hline & & & & & I0-Year lipophilic & 0.73 & $0.6-0.89$ \\
\hline & & & & & 10-Year simvastatin & 0.7 & $0.57-0.86$ \\
\hline & & & & & 10-Year hydrophilic & 1.2 & $0.79-1.7$ \\
\hline \multirow[t]{3}{*}{ Chae et al ${ }^{15}$} & Retrospective & 703 & II-III & Lipophilic (87.6\%), atorvastatin (60.2\%) & & $H R$ & $95 \% \mathrm{Cl}$ \\
\hline & & & & Hydrophilic (12.4\%) & Statins only & 0.4 & $0.24-0.67$ \\
\hline & & & & & Statins + ACEi/ARBs & 0.3 & $0.15-0.61$ \\
\hline \multirow[t]{5}{*}{ Boudreau et al ${ }^{16}$} & Prospective & 4,216 & I-IIB & $\begin{array}{l}\text { Lipophilic, simvastatin }(60.39 \%) \text {, } \\
\text { fluvastatin }(49.34 \%)\end{array}$ & & HR & $95 \% \mathrm{Cl}$ \\
\hline & & & & Hydrophilic (3.63) & $<$ I year & 0.94 & $0.5 \mathrm{I}-\mathrm{I} .75$ \\
\hline & & & & & $\mathrm{I}-2.9$ years & 0.66 & $0.34-1.30$ \\
\hline & & & & & $3+$ years & 0.77 & $0.42-1.4 \mid$ \\
\hline & & & & & Trend & 0.89 & $0.74-1.08$ \\
\hline \multirow[t]{2}{*}{ Sakellakis et a $\left.\right|^{17}$} & Retrospective & 610 & I-III & Lipophilic (64\%), atorvastatin (45\%) & & $\mathrm{HR}$ & $95 \% \mathrm{Cl}$ \\
\hline & & & & Hydrophilic (16\%) & All statin users & 0.58 & $0.36-0.94$ \\
\hline \multirow[t]{2}{*}{ Brewer et al ${ }^{18}$} & Retrospective & 73 & III (IBC) & Lipophilic (39.7\%) & & $H R$ & $95 \% \mathrm{Cl}$ \\
\hline & & & & Hydrophilic (60.3\%) & Hydrophilic only & 0.49 & $0.28-0.84$ \\
\hline \multirow[t]{2}{*}{ Lacerda et $\mathrm{al}^{39}$} & Retrospective & 53 & III (IBC) & & & $H R$ & $95 \% \mathrm{Cl}$ \\
\hline & & & & & All statin users & 0.4 & $0.16-1.00$ \\
\hline \multirow{5}{*}{$\begin{array}{l}\text { Manthravadi } \\
\text { et a }\left.\right|^{14}\end{array}$} & Meta-analysis & 75,684 & I-IV & All & & HR & $95 \% \mathrm{Cl}$ \\
\hline & & I 4 studies & & & & & \\
\hline & & & & & All statins (10 studies) & 0.64 & $0.53-0.79$ \\
\hline & & & & & Lipophilic (three studies) & 0.72 & $0.59-0.89$ \\
\hline & & & & & Hydrophilic (three studies) & 0.8 & $0.44-1.46$ \\
\hline
\end{tabular}

Abbreviations: ACEi, angiotensin-converting enzyme inhibitors; ARBs, angiotensin receptor blockers; $\mathrm{Cl}$, confidence interval; $\mathrm{HR}$, hazard ratio; IBC, inflammatory breast cancer; $\mathrm{N}$, number; $\mathrm{RR}$, relative risk.

hydrophilic or weakly lipophilic statins after initial evaluation, ie, atorvastatin (29\%), pravastatin (9\%), and rosuvastatin (1\%), while lipophilic statins were not associated with any outcome parameters. ${ }^{18}$ Note that atorvastatin in the latter study was classified as a weakly lipophilic statin and was thus analyzed with hydrophilic statins. Thus, specific types of statins may be more beneficial in patients with aggressive breast cancers.

\section{Statins and breast cancer mortality}

Various other studies suggest a survival benefit for breast cancer patients who take statins. Murtola et al followed a large cohort of Finnish patients for a median of 3.25 years and found that both pre- and postdiagnostic statin use in both localized and metastatic cases were associated with a decreased risk of death from breast cancer. Furthermore, this finding was dose dependent and time dependent for users taking statins prior to diagnosis. These parameters could not be adequately evaluated for postdiagnostic use due to a likely healthy adherer bias. Interestingly, when results were stratified according to statin type, hydrophilic statins had a benefit only when taken postdiagnostically and timing did not matter for lipophilic statins. ${ }^{19}$ In a population-based cohort study, Cardwell et $\mathrm{al}^{20}$ evaluated postdiagnostic statin use in particular and found a significant reduction in both breast cancer and all-cause mortality for simvastatin only. No associations were found for any other type of statin. Zhong et al's ${ }^{21}$ meta-analysis found that statins improved all-cause mortality for breast cancer patients when taken prior to diagnosis. Similarly, in Manthravadi et al's ${ }^{14}$ recent metaanalysis of eight and six studies, statin users had an improved OS and cancer-specific survival, respectively. Conversely, a prospective Scottish cohort study found no association between statin use and all-cause or breast cancer-specific mortality. However, a weak, nonsignificant reduction in breast cancer-specific mortality was observed in patients who took simvastatin specifically at relatively any time in relation to diagnosis $^{22}$ (refer Table 2 for an overview of the association between statin use and risk of breast cancer-specific death after multivariate analysis). 
Table 2 Overview of the association between statin use and risk of breast cancer-specific death after multivariate analysis

\begin{tabular}{|c|c|c|c|c|c|c|c|c|}
\hline Study & Type & $\mathbf{N}$ & Stage & Statins & $\begin{array}{l}\text { Risk of breast cancer } \\
\text { death }\end{array}$ & HR & Cl & Notes \\
\hline \multirow[t]{3}{*}{ Murtola et al ${ }^{19}$} & Prospective & 31,236 & $\begin{array}{l}\text { All (local vs } \\
\text { metastatic) }\end{array}$ & Simvastatin $(48.9 \%)$ & Prediagnostic statin use & 0.46 & $0.38-0.55$ & \\
\hline & & & & Atorvastatin (36.3\%) & Postdiagnostic statin use & 0.54 & $0.44-0.67$ & \\
\hline & & & & fluvastatin $(20.2 \%)$ & & & & \\
\hline \multirow[t]{2}{*}{ Cardwell et $\mathrm{al}^{20}$} & Prospective & 17,880 & All & Not specified & All statins & 0.84 & $0.68-1.04$ & Postdiagnostic \\
\hline & & & & & Simvastatin only & 0.79 & $0.63-1$ & \\
\hline \multirow[t]{2}{*}{$\begin{array}{l}\text { Mc Menamin } \\
\text { et } \mathrm{al}^{22}\end{array}$} & Prospective & 15,140 & All & $\begin{array}{l}\text { Lipophilic }(68.1 \%) \text {, } \\
\text { simvastatin }(67.8 \%)\end{array}$ & All statins & 0.95 & $0.79-1.15$ & Postdiagnostic \\
\hline & & & & Hydrophilic (35.3\%) & Simvastatin only & 0.89 & $0.73-1.08$ & \\
\hline $\begin{array}{l}\text { Manthravadi } \\
\text { et } \mathrm{al}^{14}\end{array}$ & Meta-analysis & $\begin{array}{l}75,684 \\
14 \text { studies }\end{array}$ & I-IV & All & Six studies & 0.7 & $0.46-1.06$ & \\
\hline
\end{tabular}

Abbreviations: $\mathrm{Cl}$, confidence interval; $\mathrm{HR}$, hazard ratio; $\mathrm{N}$, number.

In conclusion, since a breast cancer event cannot realistically be predicted for any one patient, we should consider primarily the effect of postdiagnostic statin use on breast cancer clinical outcomes. Nonrandomized studies suggest a clear recurrence benefit for breast cancer patients taking lipophilic statins after diagnosis, although hydrophilic or weakly lipophilic statins appear to be most effective for IBC patients in particular. Evidence is less clear regarding statins and breast cancer mortality, although a role for simvastatin specifically is apparent.

\section{Statins and breast cancer incidence}

Given the promising results detailed earlier, an important next step would be to evaluate the role of statins in breast cancer prevention. Another crucial consideration is whether or not statins have carcinogenic properties after long-term use.

Since randomized statin trials did not include breast cancer incidence as a primary endpoint, meta-analyses have been conducted to examine this relationship and they have reported no association between statin use and breast cancer risk. Studies by Bonovas et $\mathrm{al}^{23}$ and Undela et $\mathrm{al}^{24}$ examined breast cancer in particular, while others investigated cancers in general, including breast cancer ${ }^{25-28}$ (refer Table 3 for an overview of these meta-analyses). When the relationship between statins and breast cancer risk was examined as part of the Women's Health Initiative, a large US prevention study that enrolled $>160,000$ postmenopausal women aged 50-79 years over a period of 15 years; however, use of lipophilic statins was independently associated with a reduction in late-stage breast cancer diagnoses, specifically for those with estrogen receptor (ER)-positive cancers. ${ }^{29}$

When the incidence of invasive ductal carcinoma (IDC) and invasive lobular carcinoma (ILC) was examined
Table 3 Overview of meta-analyses carried out to determine the relationship between statins and breast cancer incidence

\begin{tabular}{llll}
\hline Study & Year & $\begin{array}{l}\text { Relative } \\
\text { risk }\end{array}$ & $\mathbf{9 5 \% ~ C l}$ \\
\hline Bonovas et al $^{23}$ & 2005 & 1.03 & $0.93-1.14$ \\
Dale et al $^{25}$ & 2006 & 1.02 & $0.97-1.07$ \\
Browning and Martin $^{26}$ & 2007 & 1.01 & $0.79-1.3$ \\
Kuoppala et al $^{27}$ & 2008 & 1.04 & $0.74-19$ \\
Baigent et al $^{28}$ & 2010 & 1.07 & $0.84-1.38$ \\
Undela et al $^{24}$ & 2012 & 0.99 & $0.94-1.04$ \\
\hline
\end{tabular}

Abbreviation: $\mathrm{Cl}$, confidence interval.

retrospectively in association with statin use, however, McDougall et al found that women taking statins for $\geq 10$ years had an increased risk of invasive breast disease compared to patients who had never used statins. Furthermore, stratifying by ER status, the authors found twofold increases in risk for both ER+ IDC and ILC in the statin cohort. It is unclear, though, if a prolonged history of high cholesterol is the actual culprit, as the risk of developing breast cancer was stronger for patients with higher cholesterol levels. ${ }^{30}$

Arun et al conducted a prospective short-term prevention study to evaluate the effect of atorvastatin on biomarkers in the breast tissue and serum of women at an increased risk of breast cancer, ie, those with a previous history of carcinoma in situ or atypical hyperplasia, or an increased projected breast cancer risk given by accepted models. After 3 months, patients who were randomized to take atorvastatin had significantly decreased levels of serum C-reactive protein, cholesterol, and low-density lipoprotein. Atorvastatin metabolites were found in breast biopsies. Other tested tissue biomarkers - Ki-67, bcl-2, EGFR, and pEGFR - were not significantly different between the two groups. ${ }^{31}$ Thus, 
atorvastatin may help reduce inflammation and does accumulate in breast tissue.

\section{Future studies}

Various breast cancer in vitro and animal studies have attempted to elucidate the mechanism by which statins exert their antitumor effects. In particular, the effect of statins on breast cancer invasion, migration, proliferation, apoptosis, and radiosensitivity has been studied in detail.

Preclinical data often direct clinical research, and thus, it is important to remain up to date regarding recent laboratory findings and their potential implications in the clinical arena. In particular, evidence suggests a potential role for statins in the neoadjuvant setting and/or in combination with other agents.

\section{Statins in the neoadjuvant setting}

An important question is whether or not statins have the potential to reduce tumor proliferation and/or volume neoadjuvantly. To help answer this question, Garwood et $\mathrm{al}^{32}$ randomized patients with a diagnosis of ductal carcinoma in situ or stage I breast cancer to a perioperative trial of high-dose ( $80 \mathrm{mg} /$ day) or low-dose $(20 \mathrm{mg} /$ day $)$ fluvastatin 3-6 weeks prior to surgery. The authors then examined the effect of this treatment on tumor proliferation (Ki-67 and MRI tumor volume), apoptosis (cleaved caspase-3), and inflammation (C-reactive protein). Fluvastatin significantly reduced the proliferation of high-grade tumors by $7.2 \%$, and more high-grade than low-grade tumors had an increase in apoptosis (60 vs 13\%). Results were significant regardless of whether the patients received the high-dose or the low-dose regimen. Fluvastatin also decreased median tumor size by $12.7 \%$, although this finding was not significant. Additional studies are warranted to determine whether or not statins can prove an effective neoadjuvant therapy for high-grade breast cancers.

It would be ideal to have a biomarker that could predict neoadjuvant tumor response to statin therapy and help select patients who would benefit the most from it. Bjarnadottir et al analyzed statin-induced effects on tumor proliferation in association with $\mathrm{HMG}-\mathrm{CoA}$ reductase (HMGCAR) expression in patients with invasive breast cancer. ${ }^{33}$ Patients were given high-dose atorvastatin ( $80 \mathrm{mg} /$ day) for 2 weeks prior to surgery. The authors found a significant decrease (7.6\%) in Ki-67 expression specifically for tumors expressing HMGCAR in the pretreatment sample. Furthermore, posttreatment Ki-67 expression was inversely correlated to posttreatment HMGCAR levels, implying that HMGCAR can be used as a predictive biomarker for statin tumor response. ${ }^{33}$

\section{Role for statins in inducing chemosensitivity}

The studies mentioned earlier strongly suggest that statins alone facilitate apoptosis in breast cancer cells. Their effectiveness in combination with other therapies, however, is yet to be explored. Koyuturk et a ${ }^{34}$ report that one of the mechanisms by which statins induce apoptosis is activation of the JNK-signaling pathway. Since inhibition of JNK activation is a major mechanism behind tumor resistance to cisplatin and vinblastine, ${ }^{35,36}$ perhaps the addition of statins to either of these drugs could help overcome any chemoresistance. Although these chemotherapies are more commonly used in the treatment of Hodgkin's lymphoma, non-small-cell lung cancer, bladder cancer, melanoma, head and neck cancer, and cervical cancer, it would be worth examining whether or not statins can potentiate tumor response to more conventional breast cancer chemotherapies, eg, docetaxel, doxorubicin, and cyclophosphamide (TAC).

\section{Role for statins in preventing and managing breast cancer metastases}

Although most of the studies discussed thus far included only patients with stage 0 -III breast cancer diagnoses, work by Denoyelle et $\mathrm{al}^{37}$ and Alonso et a $\mathrm{l}^{38}$ suggests a potential role for cerivastatin and lovastatin in the prevention of metastases in triple-negative breast cancer (TNBC) and sarcomatoid mammary carcinoma, respectively. The former found that in the aggressive TNBC cell line MDA-MB-231, cerivastatin inhibited the production of cholesterol precursors farnesyl pyrophosphate and geranylgeranyl pyrophosphate, which are responsible for translocation of Ras and Rho, respectively, to the cell membrane. Under normal circumstances, this final step allows the initiation of cell proliferation and migration. The introduction of cerivastatin in vitro, however, inhibited both cell proliferation and invasion through Matrigel (Becton Dickinson, Franklin Lakes, NJ, USA) and induced a loss of cell attachment in a dose-dependent manner. Alonso et a $\mathrm{l}^{38}$ found in a murine animal model of F3II sarcomatoid mammary carcinoma that lovastatin treatment prolonged tumor latency, reduced tumor formation, and decreased metastatic dissemination. Given these results, studies examining the effect of statins on clinical outcomes for metastatic breast cancer patients specifically may be warranted.

\section{Role for statins in combination with radiotherapy}

A potential role for statins as a radiosensitizer for aggressive breast cancers has been suggested in both the basic science 
and the clinical realms. We have shown that simvastatin radiosensitizes various aggressive breast cancer subtypes in vitro - namely, IBC cell lines MDA-IBC3, Sum149, and Sum190, as well as the aggressive non-IBC TNBC cell line Sum159 - as evidenced by monolayer and mammospherebased clonogenic assays. Furthermore, our findings were supported on clinical grounds, as statins were associated with a significant decrease in locoregional recurrence (LRR) rates for stage III IBC patients who underwent adjuvant radiotherapy. The actuarial 2- and 5-year local control rates for patients in the no-statin group were 76 and 69\%, respectively, and for patients in the statin group were 92 and $85 \%$, respectively. ${ }^{39}$

Resistance to radiation therapy resulting in LRR predicts a decreased OS. ${ }^{40}$ TN IBC and TNBC have especially high 5-year actuarial rates of local failure after radiotherapy: 11-35 and $45 \%$, respectively. ${ }^{41,42}$ This aggressive IBC phenotype is proposed to be caused by an enriched population of stem-like cells within these tumors. ${ }^{43-45}$ Since statins have been shown to decrease normal tissue damage following radiotherapy, ${ }^{46-48}$ they may serve a dual purpose for patients with aggressive breast cancers by, 1) radiosensitizing the tumor, and 2) permitting more aggressive protocols in the hope of further reducing LRR.

\section{Conclusion}

Statins represent a new potential therapy to improve local control and provide a benefit for patients with breast cancer. Future studies evaluating the role of statins neoadjuvantly, in combination with chemotherapies, and as a radiosensitizer are required. It is unclear if any particular statin performs exceptionally, although the prevalence of simvastatin in these studies favors better outcomes in patients with breast cancer.

\section{Disclosure}

The authors report no conflicts of interest in this work.

\section{References}

1. American Cancer Society. Cancer Facts \& Figures 2017. Atlanta: American Cancer Society; 2017.

2. Bese NS, Sut PA, Ober A. The effect of treatment interruptions in the postoperative irradiation of breast cancer. Oncology. 2005;69(3): 214-223.

3. Ohri N, Rapkin BD, Guha C, Kalnicki S, Garg M. Radiation therapy noncompliance and clinical outcomes in an urban academic cancer center. Int J Radiat Oncol Biol Phys. 2016;95(2):563-570.

4. Hershman DL, Shao T, Kushi LH, et al. Early discontinuation and nonadherence to adjuvant hormonal therapy are associated with increased mortality in women with breast cancer. Breast Cancer Res Treat. 2011;126(2):529-537.
5. McCowan C, Shearer J, Donnan PT, et al. Cohort study examining tamoxifen adherence and its relationship to mortality in women with breast cancer. Br J Cancer. 2008;99(11):1763-1768.

6. Gu Q, Paulose-Ram R, Burt V, Kit B. Prescription cholesterol-lowering medication use in adults aged 40 and over: United States, 2003-2012. NCHS Data Brief. 2014;(177):1-8.

7. Lazar LD, Pletcher MJ, Coxson PG, Bibbins-Domingo K, Goldman L. Cost-effectiveness of statin therapy for primary prevention in a low-cost statin era. Circulation. 2011;124(2):146-153.

8. Mach F. Toward a role for statins in immunomodulation. Mol Interv. 2002;2(8):478-480.

9. Mulhaupt F, Matter CM, Kwak BR, et al. Statins (HMG-CoA reductase inhibitors) reduce CD40 expression in human vascular cells. Cardiovasc Res. 2003;59(3):755-766.

10. Bellosta S, Ferri N, Bernini F, Paoletti R, Corsini A. Non-lipid-related effects of statins. Ann Med. 2000;32(3):164-176.

11. Hess DC, Fagan SC. Pharmacology and clinical experience with simvastatin. Expert Opin Pharmacother. 2001;2(1):153-163.

12. Kwan ML, Habel LA, Flick ED, Quesenberry CP, Caan B. Post-diagnosis statin use and breast cancer recurrence in a prospective cohort study of early stage breast cancer survivors. Breast Cancer Res Treat. 2008;109(3):573-579.

13. Ahern TP, Pedersen L, Tarp M, et al. Statin prescriptions and breast cancer recurrence risk: a Danish nationwide prospective cohort study. J Natl Cancer Inst. 2011;103(19):1461-1468.

14. Manthravadi S, Shrestha A, Madhusudhana S. Impact of statin use on cancer recurrence and mortality in breast cancer: a systematic review and meta-analysis. Int J Cancer. 2016;139(6):1281-1288.

15. Chae YK, Valsecchi ME, Kim J, et al. Reduced risk of breast cancer recurrence in patients using ACE inhibitors, ARBs, and/or statins. Cancer Invest. 2011;29(9):585-593.

16. Boudreau DM, Yu O, Chubak J, et al. Comparative safety of cardiovascular medication use and breast cancer outcomes among women with early stage breast cancer. Breast Cancer Res Treat. 2014;144(2):405-416.

17. Sakellakis M, Akinosoglou K, Kostaki A, Spyropoulou D, Koutras A. Statins and risk of breast cancer recurrence. Breast Cancer. 2016;8:199-205.

18. Brewer TM, Masuda H, Liu DD, et al. Statin use in primary inflammatory breast cancer: a cohort study. Br J Cancer. 2013;109(2):318-324.

19. Murtola TJ, Visvanathan K, Artama M, Vainio H, Pukkala E. Statin use and breast cancer survival: a nationwide cohort study from Finland. PLoS One. 2014;9(10):e110231.

20. Cardwell CR, Hicks BM, Hughes C, Murray LJ. Statin use after diagnosis of breast cancer and survival: a population-based cohort study. Epidemiology. 2015;26(1):68-78.

21. Zhong S, Zhang X, Chen L, Ma T, Tang J, Zhao J. Statin use and mortality in cancer patients: systematic review and meta-analysis of observational studies. Cancer Treat Rev. 2015;41(6):554-567.

22. Mc Menamin ÚC, Murray LJ, Hughes CM, Cardwell CR. Statin use and breast cancer survival: a nationwide cohort study in Scotland. BMC Cancer. 2016;16(1):600.

23. Bonovas S, Filioussi K, Tsavaris N, Sitaras NM. Use of statins and breast cancer: a meta-analysis of seven randomized clinical trials and nine observational studies. J Clin Oncol. 2005;23(34):8606-8612.

24. Undela K, Srikanth V, Bansal D. Statin use and risk of breast cancer: a meta-analysis of observational studies. Breast Cancer Res Treat. 2012;135(1):261-269.

25. Dale KM, Coleman CI, Henyan NN, Kluger J, White CM. Statins and cancer risk: a meta-analysis. JAMA. 2006;295(1):74-80.

26. Browning DRL, Martin RM. Statins and risk of cancer: a systematic review and metaanalysis. Int J Cancer. 2007;120(4):833-843.

27. Kuoppala J, Lamminpää A, Pukkala E. Statins and cancer: a systematic review and meta-analysis. Eur J Cancer. 2008;44(15):2122-2132.

28. Baigent C, Keech A, Kearney PM, et al; Cholesterol Treatment Trialists' (CTT) Collaborators. Efficacy and safety of cholesterol-lowering treatment: prospective meta-analysis of data from 90,056 participants in 14 randomised trials of statins. Lancet. 2005;366(9493):1267-1278. 
29. Desai P, Lehman A, Chlebowski RT, et al. Statins and breast cancer stage and mortality in the Women's Health Initiative. Cancer Causes Control. 2015;26(4):529-539.

30. McDougall JA, Malone KE, Daling JR, Cushing-Haugen KL, Porter PL, Li CI. Long-term statin use and risk of ductal and lobular breast cancer among women 55 to 74 years of age. Cancer Epidemiol Biomarkers Prev. 2013;22(9):1529-1537.

31. Arun BK, Gong Y, Liu D, et al. Phase I biomarker modulation study of atorvastatin in women at increased risk for breast cancer. Breast Cancer Res Treat. 2016;158(1):67-77.

32. Garwood ER, Kumar AS, Baehner FL, et al. Fluvastatin reduces proliferation and increases apoptosis in women with high grade breast cancer. Breast Cancer Res Treat. 2010;119(1):137-144.

33. Bjarnadottir O, Romero Q, Bendahl PO, et al. Targeting HMG-CoA reductase with statins in a window-of-opportunity breast cancer trial. Breast Cancer Res Treat. 2013;138(2):499-508.

34. Koyuturk M, Ersoz M, Altiok N. Simvastatin induces apoptosis in human breast cancer cells: p53 and estrogen receptor independent pathway requiring signalling through JNK. Cancer Lett. 2007;250(2) 220-228.

35. Brozovic A, Fritz G, Christmann M, et al. Long-term activation of $\mathrm{SAPK} / \mathrm{JNK}$, p38 kinase and fas-L expression by cisplatin is attenuated in human carcinoma cells that acquired drug resistance. Int J Cancer. 2004;112(6):974-985.

36. Brantley-Finley C, Lyle CS, Du L, et al. The JNK, ERK and p53 pathways play distinct roles in apoptosis mediated by the antitumor agents vinblastine, doxorubicin, and etoposide. Biochem Pharmacol. 2003;66(3):459-469.

37. Denoyelle C, Vasse M, Körner M, et al. Cerivastatin, an inhibitor of HMG-CoA reductase, inhibits the signaling pathways involved in the invasiveness and metastatic properties of highly invasive breast cancer cell lines: an in vitro study. Carcinogenesis. 2001;22(8):1139-1148.

38. Alonso D, Farina H, Skilton G, Gabri M, De Lorenzo M, Gomez D. Reduction of mouse mammary tumor formation and metastasis by lovastatin, an inhibitor of the mevalonate pathway of cholesterol synthesis. Breast Cancer Res Treat. 1998;50(1):83-93.
39. Lacerda L, Reddy JP, Liu D, et al. Simvastatin radiosensitizes differentiated and stem-like breast cancer cell lines and is associated with improved local control in inflammatory breast cancer patients treated with postmastectomy radiation. Stem Cells Transl Med. 2014;3(7):849-856.

40. Abe O, Abe R, Enomoto K, et al; Early Breast Cancer Trialists' Collaborative Group (EBCTCG). Effects of radiotherapy and of differences in the extent of surgery for early breast cancer on local recurrence and 15-year survival: an overview of the randomised trials. Lancet. 2005;366(9503):2087-2106.

41. Panoff J, Hurley J, Takita C, et al. Risk of locoregional recurrence by receptor status in breast cancer patients receiving modern systemic therapy and post-mastectomy radiation. Breast Cancer Res Treat. 2011;128(3):899-906.

42. Meyers MO, Klauber-Demore N, Ollila DW, et al. Impact of breast cancer molecular subtypes on locoregional recurrence in patients treated with neoadjuvant chemotherapy for locally advanced breast cancer. Ann Surg Oncol. 2011;18(10):2851-2857.

43. Charafe-Jauffret E, Ginestier C, Iovino F, et al. Aldehyde dehydrogenase 1-positive cancer stem cells mediate metastasis and poor clinical outcome in inflammatory breast cancer. Clin Cancer Res. 2010;16(1):45-55.

44. Rosenthal DT, Zhang J, Bao L, et al. RhoC impacts the metastatic potential and abundance of breast cancer stem cells. PLoS One. 2012;7(7):e40979.

45. Xiao Y, Ye Y, Yearsley K, Jones S, Barsky SH. The lymphovascular embolus of inflammatory breast cancer expresses a stem cell-like phenotype. Am J Pathol. 2008;173(2):561-574.

46. Ostrau C, Hülsenbeck J, Herzog M, et al. Lovastatin attenuates ionizing radiation-induced normal tissue damage in vivo. Radiother Oncol. 2009;92(3):492-499.

47. Wang J, Boerma M, Fu Q, Kulkarni A, Fink LM, Hauer-Jensen M. Simvastatin ameliorates radiation enteropathy development after localized, fractionated irradiation by a protein $\mathrm{C}$-independent mechanism. Int J Radiat Oncol Biol Phys. 2007;68(5):1483-1490.

48. Haydont V, Bourgier C, Pocard M, et al. Pravastatin inhibits the Rho/ CCN2/extracellular matrix cascade in human fibrosis explants and improves radiation-induced intestinal fibrosis in rats. Clin Cancer Res. 2007;13(18):5331-5340.
Breast Cancer - Targets and Therapy

\section{Publish your work in this journal}

Breast Cancer - Targets and Therapy is an international, peerreviewed open access journal focusing on breast cancer research, identification of therapeutic targets and the optimal use of preventative and integrated treatment interventions to achieve improved outcomes, enhanced survival and quality of life for the cancer patient

\section{Dovepress}

The manuscript management system is completely online and includes a very quick and fair peer-review system, which is all easy to use. Visit http://www.dovepress.com/testimonials.php to read real quotes from published authors. 